\title{
Systemic corticosteroids for acute gout (Review)
}

Janssens HJ, Lucassen PLBJ, Van de Laar FA, Janssen M, Van de Lisdonk EH

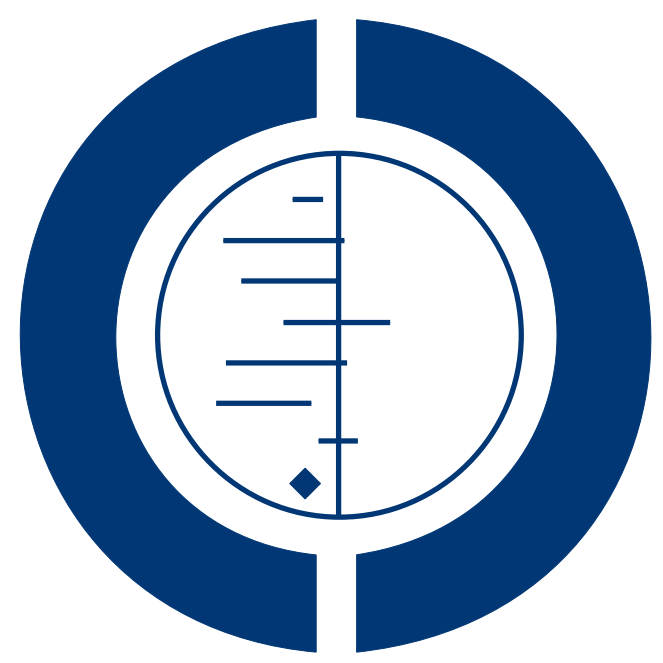

THE COCHRANE COLLABORATION $^{\circledR}$

This is a reprint of a Cochrane review, prepared and maintained by The Cochrane Collaboration and published in The Cochrane Library 2008, Issue 4

http://www.thecochranelibrary.com

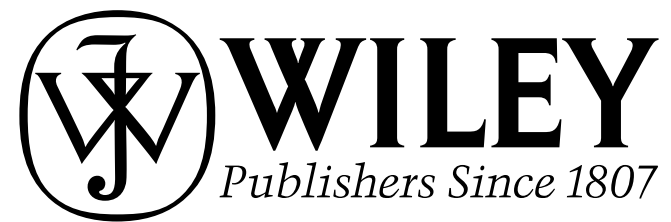

Systemic corticosteroids for acute gout (Review)

Copyright (C) 2008 The Cochrane Collaboration. Published by John Wiley \& Sons, Ltd. 
TABLE OF CONTENTS

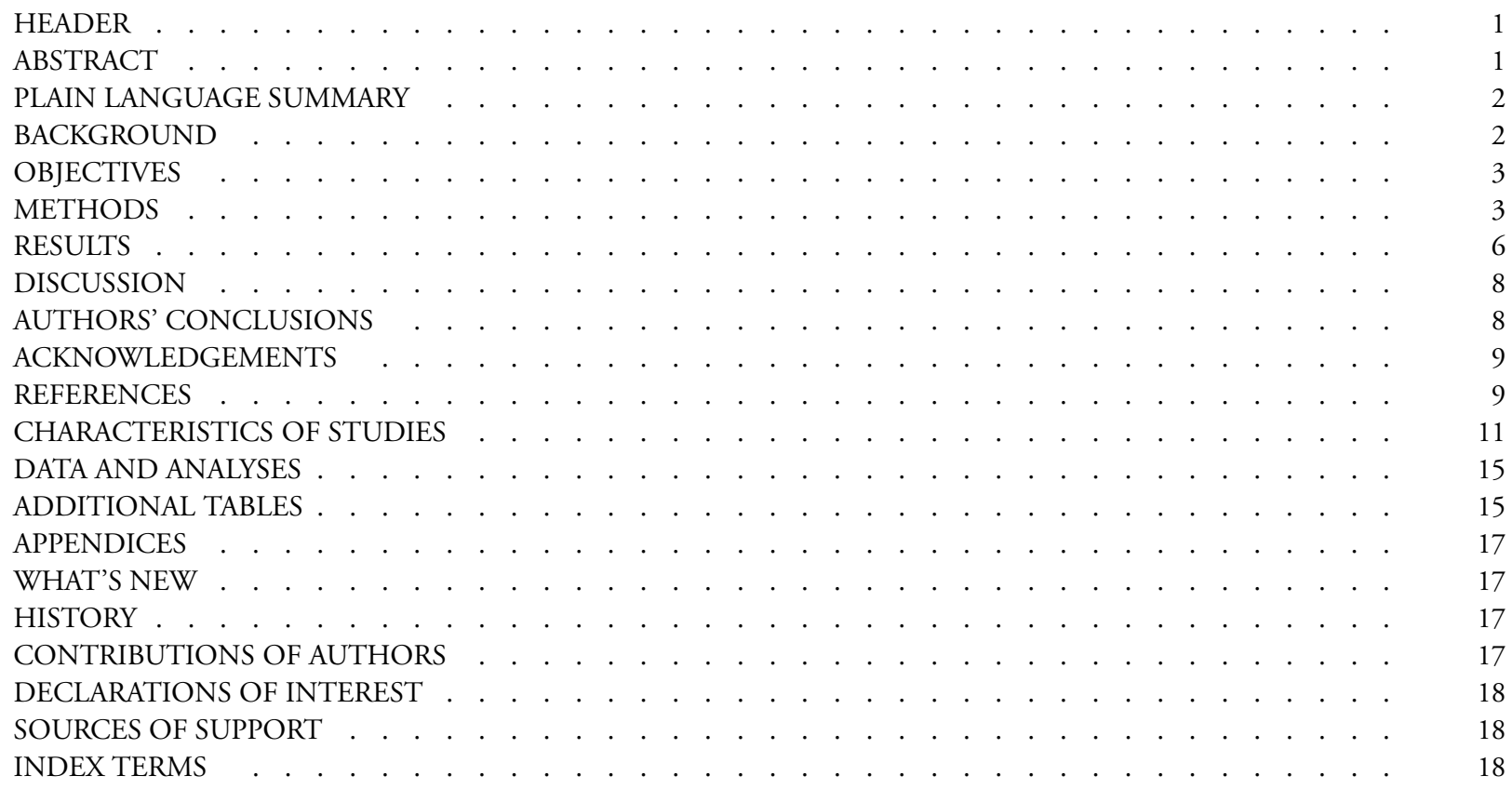




\title{
[Intervention Review]
}

\section{Systemic corticosteroids for acute gout}

\author{
Hein J Janssens ${ }^{1}$, Peter LBJ Lucassen ${ }^{2}$, Floris A Van de Laar ${ }^{3}$, Matthijs Janssen ${ }^{4}$, Eloy H Van de Lisdonk ${ }^{5}$ \\ ${ }^{1}$ Lobith, Netherlands. ${ }^{2}$ Department of General Practice and Family Medicine, Radboud University Medical Centre, Nijmegen, \\ Netherlands. ${ }^{3}$ Department of General Practice, 117 HAG, Radboud University Nijmegen Medical Centre, Nijmegen, Netherlands. \\ ${ }^{4}$ Rheumatology, Rijnstate Hospital Arnhem, Arnhem, Netherlands. ${ }^{5}$ Department of General Practice and Family Medicine, 117 HAG, \\ Radboud University Medical Centre Nijmegen, Nijmegen, Netherlands
}

Contact address: Hein J Janssens, Transeedijk 62, Lobith, 6915 XZ, Netherlands. h.janssens2@chello.nl.

Editorial group: Cochrane Musculoskeletal Group.

Publication status and date: Edited (no change to conclusions), published in Issue 4, 2008.

Review content assessed as up-to-date: 7 December 2007.

Citation: Janssens HJ, Lucassen PLBJ, Van de Laar FA, Janssen M, Van de Lisdonk EH. Systemic corticosteroids for acute gout. Cochrane Database of Systematic Reviews 2008, Issue 2. Art. No.: CD005521. DOI: 10.1002/14651858.CD005521.pub2.

Copyright (c) 2008 The Cochrane Collaboration. Published by John Wiley \& Sons, Ltd.

\section{A B S T R A C T}

\section{Background}

Gout is one of the most frequently occurring rheumatic diseases, worldwide. Given the well-known drawbacks of the regular treatments for acute gout (non-steroidal anti-inflammatory drugs (NSAIDs), colchicine), systemic corticosteroids might be safe alternatives.

\section{Objectives}

To assess the efficacy and safety of systemic corticosteroids in the treatment of acute gout in comparison with placebo, NSAIDs, colchicine, other active drugs, other therapies, or no therapy.

\section{Search methods}

Searches were done in the following electronic databases: Cochrane Central Register of Controlled Trials (CENTRAL) (The Cochrane Library 2007); MEDLINE (1966 to 2007) through PubMed; EMBASE (1974 to 2007); Web of Science (1975 to 2007); LILACS (1986 to 2007); and databases of ongoing trials (up to April 2007).

\section{Selection criteria}

Randomized controlled trials and controlled clinical trials investigating the use of systemic corticosteroids in the treatment of acute gout were included.

\section{Data collection and analysis}

Two review authors decided independently which trials to include. The same review authors also collected the data in a standardised form and assessed the methodological quality of the trial using validated criteria. When possible, continuous and dichotomous data were summarised statistically.

\section{Main results}

Three head to head trials involving 148 patients (74 systemic corticosteroids; 74 comparator drugs) were included. Placebo-controlled trials were not found. In the studies, different kinds of systemic corticosteroids and different kinds of control drugs were used, both administered in different routes. Intramuscular triamcinolone acetonide was compared respectively to oral indomethacine, and intramuscular adrenocorticotropic hormone (ACTH); oral prednisolone (together with a single intramuscular diclophenac injection) was compared to oral indomethacine (together with a single placebo injection). Outcome measurements varied: average number of 
days until total relief of signs, mean decrease of pain per unit of time in mm on a visual analogue scale (VAS) - during rest and activity. In the triamcinolone-indomethacine trial the clinical joint status was used as an additional outcome. Clinically relevant differences between the studied systemic corticosteroids and the comparator drugs were not found; important safety problems attributable to the used corticosteroids were not reported. The quality of the three studies was graded as very low to moderate. Statistical pooling of results was not possible.

\section{Authors' conclusions}

There is inconclusive evidence for the efficacy and effectiveness of systemic corticosteroids in the treatment of acute gout. Patients with gout did not report serious adverse effects from systemic corticosteroids, when used short term.

\section{PLAIN LANGUAGE SUMMARY}

\section{Systemic corticosteroids for acute gout}

This summary of a Cochrane review presents what we know from research about the effect of systemic corticosteroids for acute gout. The review shows that in people with gout:

- systemic corticosteroids may slightly improve patients' assessment of pain and disability. However, this could have occurred by chance;

- there is no precise information about side effects and complications. Only a minority of the patients treated with the steroid oral prednisolone reported minor side effects.

\section{What is gout, and what are systemic corticosteroids?}

Gout is a sudden, very painful joint inflammation (arthritis). It usually affects the big toe. The inflammation, which is caused by urate crystals, leads to swelling and redness of the joint, and makes it painful to move or even to touch.

Systemic corticosteroids are drugs that imitate the corticosteroids that are naturally produced by your own body and may help reduce swelling, redness and pain in joints. Systemic corticosteroids come in a pill form or as an injection given by your doctor.

\section{B A C K G ROU N D}

Gout is a frequently occurring form of arthritis, mostly localized in the first metatarsophalangeal joint, with the tendency to recur easily. It is an extremely painful acute inflammatory arthritis with a sudden and dramatic onset, often beginning at night (Schumacher 1996; Schlesinger 2004). The arthritis wanes over days to weeks, with or without treatment (Bellamy 1987; Arnold 1988). The severe and painful inflammation is caused by the deposition of monosodium urate (MSU) crystals in the affected joint. The identification of these MSU crystals in the synovial fluid after joint aspiration and microscopic investigation comprises the gold standard for diagnosis. It is thought that the MSU crystal deposition in the joint is a consequence of high serum urate levels, caused by metabolic overproduction or renal undersecretion, or both (Bieber 2004). Uric acid is an end product of purine nucleotide catabolism and is excreted largely by the kidneys. Gout affects at least $1 \%$ of adult men in their lifetime, in Western countries (Terkeltaub 2003; Bieber 2004). The estimated incidence of gout in these countries is 0.6 to 2.1 per 1000 per year (Arromdee 2002; Van de Lisdonk 2003; Schlesinger 2004; Van der Linden 2004), with a prevalence of 3 to 7.5 per 1000 per year (Van de Lisdonk 2003; Schlesinger 2004; Van der Linden 2004).

In current practice, non-steroidal anti-inflammatory drugs (NSAIDs) and colchicine are the most commonly used agents for the treatment of acute gout (Kim 2003; Terkeltaub 2003; Schlesinger 2004).

In the past decades several studies have shown effectiveness of NSAIDs in patients with acute gouty arthritis in reducing pain, swelling, disability, redness and temperature (Sturge 1977; Altman 1988; Maccagno 1991; Shrestha 1995; Schumacher 2002; Rubin 2004; Sutaria 2006). Despite the fact that a recent systematic review located only one placebo-controlled NSAID study, NSAIDs are widely accepted as the drugs of first choice (Sutaria 2006). Gastrointestinal complications like gastritis, ulceration, bleeding, and perforation are the most frequent adverse effects of NSAIDs. 
These adverse effects can emerge even within a short period of use (Lewis 2002). Other less frequent side effects of NSAIDs are allergic symptoms, headache, dizziness, and sleepiness. Furthermore, decreased renal function in patients with chronic gout has been attributed to the use of NSAIDs (Perez-Ruiz 2000). Finally, NSAIDs have drawbacks secondary to age and cardiovascular risks, in particular myocardial infarction, loss of renal function, fluid retention, and concurrent use of anticoagulants (Lewis 2002; Kim 2003; Schlesinger 2004; Kearney 2006, Sutaria 2006, Underwood 2006). These drawbacks can be expected in gout patients as they are generally older and often have pre-existing co-morbidities, like renal and cardiovascular disease (Abbott 1988; Conaghan 1994; Fam 1998; Janssens 2003; Bieber 2004; Janssens 2006; Krishnan 2006).

Colchicine has a longstanding history in the treatment of acute gout, even before NSAIDs were available. It is considered a first alternative when NSAIDs are contraindicated. It has a narrow therapeutic window with hazardous side effects, even when patients are treated according to accepted guidelines (Morris 2003). The evidence for its therapeutic use in acute gout is based on one placebocontrolled trial (Ahern 1987). This was the conclusion of a recent Cochrane systematic review (Schlesinger 2006). High doses are advised until relief of pain is obtained, or vomiting or diarrhoea occurs (Conaghan 1994; Morris 2003). The plasma half-life of colchicine is longer when renal function is impaired, a condition which is often seen in gout patients (Wise 1996; Petersel 2007). Other infrequent but serious side effects are bone marrow suppression, myopathy, and neuropathy (Conaghan 1994).

There are arguments to re-appraise the routine status of NSAIDs and colchicine in the treatment of acute gout because of their contraindications and adverse effects (Sutaria 2006). Alternatives with a better risk benefit profile are needed because it can be expected that many gout patients are at risk on routine treatment with NSAIDs and colchicine. Corticosteroids are often mentioned to be such an alternative, particularly in elderly people, as they have potentially effective anti-inflammatory capacity and may have fewer adverse effects when used short term (Groff 1990; Fam 1998; Rowe 2001; Kim 2003; Terkeltaub 2003; Schlesinger 2004; Gotzsche 2005; Sutaria 2006; Underwood 2006). We were aware of a few studies investigating short-term treatments of gout with systemic corticosteroids, which demonstrated treatment effects (Groff 1990, Alloway 1993, Siegel 1994, Werlen 1996). However, these studies had only small numbers of patients, they investigated different types of corticosteroids, and showed considerable methodological differences. We were not able to find systematic reviews on this topic, systemic corticosteroids for acute gout. The reviews that we did find were predominantly narrative, without a predefined systematic method, or without a focus on corticosteroids (Groff 1990; Schumacher 1996; Wise 1996; Terkeltaub 2003; Schlesinger 2004; Sutaria 2006).

\section{O B J E C T IV E S}

To assess the efficacy and safety of systemic corticosteroids in the treatment of acute gout in comparison with placebo, NSAIDs, colchicine, other active drugs, other therapies, or no therapy.

\section{MET HO D S}

\section{Criteria for considering studies for this review}

\section{Types of studies}

Randomized controlled trials and controlled clinical trials investigating the use of systemic corticosteroids in the treatment of acute gout were eligible for inclusion.

\section{Types of participants}

Patients of any age with an acute gouty arthritis diagnosed after identification of MSU crystals were considered for this review. Because of the expected limited number of trials adhering to this criterion, we also considered trials involving patients with a gout diagnosis according to the preliminary criteria of the American College of Rheumatology, the ACR criteria (Wallace 1977), or based on other clinical grounds.

\section{Types of interventions}

Only studies that evaluated the benefit or safety of a mono-therapy with systemic corticosteroids were eligible for inclusion. We searched for all studies that compared this therapy with placebo, NSAIDs, colchicine, other active drugs, other therapies, or no therapy.

\section{Types of outcome measures}

Primary outcomes were based on patients' assessment of pain and disability, investigators' assessment of clinical symptoms (swelling, erythema, tenderness), and adverse events. If eligible, secondary outcomes such as cost-effectiveness were also considered.

\section{Search methods for identification of studies}

See: Cochrane Musculoskeletal Group methods used in reviews. Searching was performed as outlined in the Cochrane Handbook for Systematic Reviews of Interventions. The following electronic databases were used for the identification of the trials.

* The Cochrane Library, including the Cochrane Central Register of Controlled Trials (CENTRAL) (up to 2007).

* PubMed (including MEDLINE) (1966 to 2007). 
* EMBASE (1974 to 2007).

* Web of Science (1975 to 2007).

* LILACS (www.bireme.br/bvs/I/ibd.htm) (1986 to 2007).

* Databases of ongoing trials (up to April 2007).

Ongoing trial databases included: Current Controlled Trials (http: //www.controlled-trials.com, with links to other databases of ongoing trials); UK National Research Register (http://www.updatesoftware.com/National/nrr-frame.html); USA Center Watch Clinical Trials Listing Service (http://www.CenterWatch.com/ ); USA National Institutes of Health (http://clinicalstudies.info.nih.gov/).

We performed a search combining search procedures for clinical trials, gout, and systemic corticosteroids (see below). We combined these procedures with the Boolean operator AND. In the strategy for clinical trials we used a sensitive and valid procedure (Robinson 2002); in the search strategy for gout and corticosteroids we developed a strategy using keywords (MeSH headings) and text words. We tested our procedures extensively by running the searches and subsequently checking whether known articles on the topic of gout or corticosteroids were missing.

The search strategy for PubMed is given below (see Appendix 1 as well).

\#1 Gout

"gout" [mh] OR gout* [tw] OR "Hyperuricemia" [mh] OR toph* [tw] OR arthritis uric* [tw] OR artritis uric* [tw] OR uric acid dis* [tw] $^{*}$

\#2 Corticosteroids

"Glucocorticoids" [mh] OR "Adrenal Cortex Hormones" [mh] OR "Steroids" [mh] OR glucocortic* [tw] OR adrenal Cortex Horm* [tw] OR prednison* [tw] OR prednisol* [tw] OR cortison* [tw] OR hydrocort* [tw] OR methylprednis* [tw] OR triamcinol* [tw] OR dexamethas* [tw] OR betamethas* [tw] OR beclomethas* [tw] OR paramethas* [tw] OR dexametas* [tw] OR betametas* [tw] OR beclometas* $[\mathrm{tw}]$ OR parametas* $[\mathrm{tw}]$

\#3 Controlled trials

(Randomized controlled trial [pt] OR controlled clinical trial [pt] OR randomized controlled trials [mh] OR random allocation [mh] OR double-blind method [mh] OR single-blind method [mh] OR clinical trial [pt] OR clinical trials [mh] OR (clinical trial $[\mathrm{tw}])$ OR ((singl*[tw] OR doubl* [tw] OR trebl* [tw] OR tripl* $^{*}$ [tw]) AND (mask* [tw] OR blind* [tw])) OR (latin square [tw]) OR placebos [mh] OR placebo* [tw] OR random* [tw] OR research design [mh:noexp] OR comparative study [mh] OR evaluation studies [mh] OR follow-up studies [mh] OR prospective studies [mh] OR cross-over studies [mh] OR control* [tw] OR prospectiv* $\left.^{*} \mathrm{tw}\right]$ OR volunteer* [tw]) NOT (animal [mh] NOT human $[\mathrm{mh}]$ )

Whole search

\#1 AND \#2 AND \#3

Abbreviations: mh: exploded medical subject heading (Medline medical index term); mh:noexp: non-exploded medical subject heading (MEDLINE medical index term); $\mathrm{tw}=$ text word; $\mathrm{pt}=$ publication type. The asterisk $\left({ }^{*}\right)$ stands for any character(s). For EMBASE and Current Contents, this strategy was adapted because these databases have different interfaces. The necessary changes in the search string were done so that the search became more sensitive (that is yielded a higher number of 'hits').

\section{Data collection and analysis}

\section{Study selection}

To select studies for further assessment, two review authors (HJ and PL) independently reviewed the titles and abstracts of every record retrieved. Articles were selected if this information indicated that the study: (1) included patients with crystal-proven gout or patients with a gout diagnosis based on the preliminary criteria of the ACR, or with a diagnosis on other clinical grounds; (2) compared systemic corticosteroid treatment with placebo or other interventions; (3) assessed one or more of the required outcome measures; (4) used random allocation [or for controlled clinical trials, an allocation under the control of the investigator] to the comparison groups. If there was any doubt regarding the information from the title and abstract, the full article was retrieved for clarification. In a case of disagreement about including a study, a third review author (EvdL) was consulted for a definitive decision. Inter-observer agreement for study selection was measured using the kappa statistic (Cohen 1960).

\section{Quality assessment of the selected studies}

Two review authors (HJ and PL) assessed the quality of each retrieved trial independently using the following quality characteristics.

1. Selection bias. A) Method of randomization: the randomization procedure was scored as adequate when the resulting sequences were unpredictable (i.e., computer generated schemes, tables of random numbers, coin tossing). B) Allocation concealment: scored as adequate when participating patients and investigators could not foresee assignment (i.e., by central randomization remote from trial site, sequentially numbered and sealed radioopaque envelopes).

2. Performance bias. Methods of (double) blinding, if applicable: blinding was considered adequate when the interventions were similar in size, colour, and shape; or when a double dummy method was applied. If trials reported blinding we also investigated whether the blinding was checked.

3. Attrition bias. A) Description of withdrawals and drop-outs: handling of drop-outs was considered adequate when studies gave a complete description of all patients failing to participate until the end of the trial and when the data were analysed on an intention-to-treat (ITT) basis. B) Number of drop-outs: overall dropout rate $<15 \%$ was considered adequate. C) Selective drop-out: a difference in drop-out rate between the groups $<10 \%$ was considered adequate. 
4. Detection bias. Method of blinding outcome assessment: this blinding was considered adequate if the researchers assessing the outcomes were completely blinded for the intervention.

In a case of disagreement regarding the assessment of the quality characteristics, one of the other review authors ( FvdL) was invited to make the final decision.

In addition to these criteria, studies were broadly subdivided into the following three quality scores, as recommended in the Cochrane Handbook for Systematic reviews of Interventions (Higgins 2005).

A - All quality criteria met: 1 . adequate randomization and allocation concealment, 2. adequate blinding, 3. adequate ITT analysis or drop-out rate less than $15 \%$ and selective drop-out less than $10 \%$, or both; low risk of bias.

B - One or more quality criteria only partially met: 1 . adequate randomization or adequate allocation concealment, 2. mentioning of blinding but exact method unclear, 3. inadequate or unclear ITT analysis but drop-outs less than $15 \%$ or selective drop-out less than $10 \%$ ); moderate risk of bias.

C - One or more quality criteria not met: 1 . inadequate randomisation and allocation concealment, 2 . inadequate or no blinding, 3. inadequate ITT and drop-out rate equal to or greater than $15 \%$ and selective drop-out equal to or greater than $10 \%$; high risk of bias.

\section{Data extraction}

Two review authors (HJ and PL) independently extracted the data concerning characteristics of the selected studies by using a standard form. This form included the following items.

1. General aspects: title, authors, source, contact address; language of publication; year of publication; duplicate publication; sponsoring.

2. Trial characteristics: design and setting; randomization (and method); allocation concealment (and method); blinding (patients, people administering treatment, outcome assessors) and check of successful blinding.

3. Intervention details: placebo or comparison interventions, or both (dose, route, timing); co-medication or other accompanying treatment (dose, route, timing).

4. Participant details: sampling (random or convenience); exclusion criteria; total number and numbers in the comparison groups; age, sex, and other baseline characteristics; diagnostic criteria; only new or all cases; assessment of compliance; withdrawals and losses to follow up (reasons, description).

5. Outcome measures and methods of assessing outcomes: continuous scales (e.g., visual analogue scales); dichotomous outcomes (e.g., presence or absence of pain); categorical scales (e.g., none, mild, moderate, severe, extreme); validated questionnaires; or other reported methods (e.g., amount of days required for total resolution of all symptoms); and length of follow up.

Data analysis
We planned to summarize the data statistically, if available and sufficiently homogeneous.

We expected dichotomous, ordinal, and continuous data. If possible, dichotomous data were expressed as relative risks (RR). Peto odds ratio (Peto OR) were used when incidence rates were small. We expressed continuous data as weighted mean differences (WMD) when outcomes were measured in a similar way. In all other cases, standardized mean differences (SMD) were used.

We intended to calculate the overall results based on the randomeffects model; to test the heterogeneity using the Z-score and the Chi-square statistic (significance level $\mathrm{P}<0.10$ ); and to quantify the effect of heterogeneity by means of the $\mathrm{I}^{2}$ statistic, ranging from 0 to $100 \%$ including its $95 \%$ confidence interval. $\mathrm{I}^{2}$ demonstrates the percentage of total variation across studies due to heterogeneity, and it could be used to judge the consistency of the evidence (Higgins 2002). A value greater than $50 \%$ may be considered as substantial heterogeneity. Possible sources of heterogeneity were assessed by sensitivity and subgroup analyses. Publication bias was tested using a funnel plot.

The analyses were performed with the most recent version of RevMan Analyses in Review Manager.

\section{Sensitivity and subgroup analyses}

We preplanned sensitivity analyses to evaluate the influence on the effect size of the following.

1. Published versus unpublished studies, if any.

2. Studies with or without certain quality characteristics: adequate randomization; adequate allocation concealment; adequate method of blinding; adequate ITT analyses; adequate blinding for outcome assessment; adequate method of blinding of analyses; an overall drop-out rate less than $15 \%$; difference of drop-out rates between the main treatment groups less than $10 \%$; a quality score A or B, as recommended in the Cochrane Handbook for Systematic reviews of Interventions (compared to studies with score of C)(Higgins 2005).

3. Small versus large studies.

4. English language versus other than English language.

5. Sponsored by industry versus other or no industry funding.

6. Gout diagnosis based on identification of MSU crystals versus no crystal identification.

We also preplanned subgroup analyses to explore the influence on effect sizes of the following variables.

1. Age.

2. Gender.

3. The route of administration (oral, rectal, intramuscular).

4. Type of steroid.

5. Dose (low, medium, high; based on data).

6. Duration of intervention.

7. Diagnosis criteria (crystal proven, according to ACR, other).

8. Race.

9. Blood level of uric acid.

Finally, for the exploration of the robustness of the results, we 
planned to repeat the analysis using different measures of effect size (relative risk, risk difference) and different statistical models (fixed-effect and random-effects models).

\section{Clinical relevance tables}

When data were appropriate, we planned to compile clinical relevance tables to improve the readability of the review. For dichotomous outcomes, we planned to calculate the number needed to treat from the relative risk, using the Visual Rx NNT Calculator (Cates 2003). For continuous outcomes and when possible, the absolute benefit as the difference between the improvement in the intervention group and the improvement in the control group was assessed in the units as given in the original publication. Moreover, we intended to calculate the relative difference in improvement as the difference of the percentage change in the intervention group and the percentage change in the control group.

\section{R E S U L T S}

\section{Description of studies}

See: Characteristics of included studies; Characteristics of excluded studies; Characteristics of ongoing studies.

We identified 2083 study titles and abstracts from the predefined databases. Eight of 2083 were independently selected by the two review authors (HJ and PL) to retrieve the full article with the aim of evaluating the definite eligibility for inclusion in the review. The inter-observer agreement of this selection procedure, expressed as kappa, was 0.93 (95\%CI 0.80 to 1.00 ; standard error 0.067).

After reading the full publication, both authors independently concluded that four of the eight studies did not meet the inclusion criteria (Axelrod 1988; Groff 1990; Conaghan 1994; Werlen 1996). One study was retrieved from trial registers (ISRCTN14648181). This study is being conducted by our own group, and to date the data are not analysed or published. Finally, we selected three studies for inclusion (Alloway 1993; Siegel 1994; Man 2007).

In the first included study, intramuscular injections with triamcinolone acetonide were compared with oral indomethacine (Alloway 1993). In this study the diagnosis of gout in the 27 participants (all male) was confirmed by identification of MSU crystals. Afflicted joints were not described. The mean number of involved joints per patient was more than two. Exclusion criteria were: any infectious process, anticoagulant therapy, uncontrolled diabetes mellitus. Patients currently taking colchicine, allopurinol, or an uricosuric agent were allowed to continue this medication during the study. Triamcinolone acetonide-treated patients were given paracetamol with codeine for analgesia. Fourteen patients (mean age 61.2 years) were injected once with $60 \mathrm{mg}$ triamcinolone acetonide and, if necessary, an additional injection. Patients were eligible to receive a second injection if they had less than
$50 \%$ improvement at the first follow up. Three patients received a second injection two days after entry in the study. Thirteen patients (mean age 62.8 years) received indomethacine tablets, 50 $\mathrm{mg}$ three times a day, with permission to taper their medication after at least two days in response to symptomatic improvement. An important difference between the two treatment groups at baseline was that five patients in the triamcinolone acetonide group versus one patient in the indomethacine group used colchicine. Seven patients were lost to follow up (four in the triamcinolone acetonide group, three in the indomethacine group). Patients were evaluated by an unblinded observer at 1 to 2,3 to 4,10 to 14 , and 30 days for symptomatic improvement (using a 5-point-scale: total resolution, improvement of $>50 \%$, improvement of $<50 \%$, no change, worsening of symptoms or involvement of previously uninvolved joints), for the number of active joints, the presence of toxicity to therapy, and the presence of rebound arthropathy. The final efficacy outcomes were the number of days required for total resolution of all symptoms, and the clinical joint status at 3 follow-up moments.

In the second study, intramuscular injections with triamcinolone acetonide were compared with intramuscular injections of adrenocorticotropic hormone (ACTH) (Siegel 1994). All 31 patients (all male) had their diagnosis of acute gout confirmed by joint aspiration of MSU crystals. Afflicted joints were not described. The mean number of involved joints was more than 2.5 for each patient. Patients with a history of uncontrolled diabetes, congestive heart failure, infection, or severe coronary artery disease were excluded. Patients currently taking colchicine, allopurinol, or an uricosuric agent were allowed to continue this medication during the study. Sixteen patients (mean age 62.4 years) were injected with $60 \mathrm{mg}$ triamcinolone acetonide and, if necessary, one or more additional injections. Fifteen patients (mean age 69.6 years) were given 40 IU ACTH intramuscularly and, if necessary, one or more additional injections. One patient allocated to ACTH treatment was lost to follow up for unknown reasons. Patients were eligible for a repeat injection if they had $<50 \%$ improvement at each subsequent follow-up visit. Two patients in the ACTH group did not reach a 50\% improvement after three injections and were treated with triamcinolone acetonide, but were not analysed. The time interval between re-injections was not reported. There were no statistical differences between the two treatment groups at baseline, except for a higher erythrocyte sedimentation rate (ESR) in the triamcinolone acetonide group: 45.57 versus 40.25 (P-value 0.003). The researchers did not consider this difference clinically relevant. Patients were evaluated by unblinded (different) observers at 1 to 2, 3 to 4,10 to 14 , and 30 days for symptomatic improvement (using a 5-point-scale: total resolution, improvement of $>50 \%$, improvement of $<50 \%$, no change, worsening of symptoms or involvement of previously uninvolved joints), for the number of active joints, for the clinical joint status, for side effects, and for rebound arthropathy. The final efficacy outcome was the number of days to $100 \%$ resolution of the symptoms. 
In the third included trial, oral prednisolone was compared to intramuscular diclophenac combined with oral indomethacine (Man 2007). Diagnosis of all 90 patients in this study was based on clinical judgement, without predefined criteria. Afflicted joints were not described. In more than $90 \%$ of the patients a single joint was involved, most of the time in the lower limb. Exclusion criteria were: clinical suspicion of sepsis or other joint disease; lack of transport or telephone after diagnosis; significant co-morbidity that would interfere with assessment; dementia or confusion; active gastrointestinal symptoms; serum creatine level greater than $200 \mathrm{mmol} / \mathrm{l}$; bleeding disorder; allergy to a study drug; joint aspiration that excluded the diagnosis of gout. Patients were instructed to use paracetamol (1 gram every 4 hours) as required. All patients in the diclophenac plus indomethacine group $(\mathrm{N}=$ 46 , mean age 66 years) received an intramuscular injection of 75 $\mathrm{mg}$ diclophenac at the start of the trial, and $50 \mathrm{mg}$ indomethacine three times a day for two days then $25 \mathrm{mg}$ indomethacine three times a day for three days. Patients in the predisolone group $(\mathrm{N}$ $=44$, mean age 64 years) received an initial placebo injection and $30 \mathrm{mg}$ prednisolone daily for five days. There were no important differences between the treatment groups at baseline. The mean rate of decrease in pain at rest and with activity during the first two hours and at five-day follow ups were the primary outcomes, assessed with a $100 \mathrm{~mm}$ visual analogue scale. Medication was stopped In seven patients of the diclophenac plus indomethacine group after serious gastrointestinal adverse effects.

\section{Risk of bias in included studies}

We summarized the quality of the included trials in Table 1 . With respect to selection bias, only one study had both adequate randomization and adequate allocation concealment (Man 2007). The risk of attrition bias (degree of drop-out and selective dropout) was low in one study (Siegel 1994). An adequate intention-totreat analysis was only performed in one study (Man 2007). Blinding (performance bias) was adequate in one study (Man 2007). The other studies were not blinded. Outcome assessment in all studies was not blinded or no information was provided. The overall quality scored according to the three-point scale recommended in the Cochrane Handbook for Systematic Reviews of Interventions was B (moderate risk of bias) for one study (Man 2007) and $\mathrm{C}$ (high risk of bias) for the two other studies.

\section{Effects of interventions}

\section{Efficacy}

The efficacy of the three included studies (involving 148 patients) are summarised in Table 2. From the included studies we extracted six different outcome measures which represented treatment efficacy, and provided enough data to analyze them. It should be noted that if systemic corticosteroids are more effective than the comparative drugs the presented mean difference is positive. The average number of days until complete resolution of symptoms The mean differences in the average number of days until complete resolution of symptoms, between triamcinolone acetonide and indomethacine, and triamcinolone acetonide and ACTH were 0.9, and 0.3 days respectively (P-values 0.66 , and 0.89 ; measures of uncertainty, for example $95 \% \mathrm{CI}$, were not reported).

Clinical joint status at three follow-up moments

On comparing triamcinolone acetonide and indomethacine, the differences between the mean clinical joint scores after 1 to 2,3 to 4 , and 10 to 14 days respectively, as assessed by an unblinded investigator, were $0.5,0.03$, and -0.3 on a 5 -point categorical scale (P-values $0.24,0.94$, and 0.25 respectively; measures of uncertainty, for example $95 \% \mathrm{CI}$, were not reported).

Reduction of the pain at rest per hour during the first two hours

Regarding pain reduction during the first two hours after the start of the treatment, as assessed by the patient on a VAS of $100 \mathrm{~mm}$, the mean difference between prednisolone and diclophenac plus indomethacine was $3.2 \mathrm{~mm}$ per hour for pain at rest $(95 \% \mathrm{CI}$ 0.78 to 7.14$)$.

Reduction of the pain with activity per hour during the first two hours The mean difference between prednisolone and diclophenac plus indomethacine was $-1.1 \mathrm{~mm}$ for the reduction of pain during activity (95\% CI -5.34 to 3.24$)$.

Reduction of the pain at rest per day after two weeks

Regarding the decrease of the pain at rest during the first two weeks, the mean difference was $0.5 \mathrm{~mm}$ per day (95\% CI 0.03 to 0.89 ) comparing prednisolone and diclophenac plus indomethacine.

Reduction of the pain with activity per day after two weeks

For the reduction of the pain with activity after two weeks, the mean difference was $1.2 \mathrm{~mm}$ (95\% CI 0.44 to 2.00 ) comparing prednisolone and diclophenac plus indomethacine.

We did not perform clinical relevance tables for pain or any other major outcome as the two triamcinolone acetonide studies did not provide adequate data for this, and the difference in the pain outcome at the end of the follow up in the third study was statistically not significant.

\section{Adverse events}

No adverse effects were reported in the triamcinolone acetonidetreated patients or in the ACTH-treated patients (Alloway 1993; Siegel 1994). In the indomethacine group of the first trial, $20 \%$ of the patients noted dyspepsia (Alloway 1993). In the third study, statistically significant differences were found in adverse events between the prednisolone-treated patients and the diclophenac plus indomethacine-treated patients: $27 \%$ versus $63 \%$ for any adverse event; and $0 \%$ versus $15 \%$ for serious adverse effects requiring hospital admission (11\% gastrointestinal bleeding) (Man 2007). Adverse effects in the diclophenac plus indomethacine group were: epigastric pain (30\%), other abdominal pain (7\%), rash (2\%), dizziness (19\%), drowsiness (19\%), dry mouth (24\%), indigestion $(30 \%)$, nausea $(26 \%)$, vomiting $(9 \%)$, diarrhoea $(7 \%)$, gastroin- 
testinal haemorrhage (11\%), shortness of breath $(2 \%)$, and chest pain $(2 \%)$; and in the prednisolone group: rash $(7 \%)$, dizziness $(5 \%)$, drowsiness (16\%), dry mouth (20\%), indigestion (9\%), and nausea (9\%) (Man 2007).

As there were no clinically important adverse events related to the studied systemic corticosteroids, we had no reason to compile a clinical relevance table.

\section{Sensitivity analyses}

We did not perform any sensitivity analyses as the number of studies included in our review was too small.

\section{DISCUSSION}

In this systematic review we retrieved three studies, including 74 patients with acute gout, that involved treatment with systemic corticosteroids. There were no placebo-controlled studies. All were active comparator-controlled trials. None of the studies reported clinically relevant differences between the systemic corticosteroids and the comparator drugs. No important safety problems attributable to the corticosteroids were found. Most adverse events were related to the comparator drugs, in particular to the NSAIDs.

Conclusions from the present review about the efficacy, effectiveness, and safety of systemic corticosteroids in the treatment of acute gout must be interpreted cautiously, for the following reasons.

1. The use of comparator drugs in controlled trials presupposes efficacy of the comparator drug. However, there is hardly any evidence for the efficacy of the comparator drugs that were used. Although the efficacy of NSAIDs is generally accepted, we were aware of only one placebo-controlled study showing efficacy of NSAIDs (Sutaria 2006). We were not aware of evidence for the efficacy of ACTH and, regarding its effectiveness, we located only one comparator-controlled study (Axelrod 1988).

2. None of the studies were designed to show equivalence. Therefore, if study outcomes do not show statistical differences ( $\mathrm{P}>$ $0.05)$ this does not designate the existence of equal effectiveness of the studied drugs regarding these outcomes (Jones 1996).

3. The methodological quality of the included studies is very low; according to the Cochrane Handbook for Systematic reviews of Interventions two of the three studies were scored $\mathrm{C}$, indicating very low quality (Alloway 1993; Siegel 1994). The third study was scored B (Man 2007), indicating moderate quality.

4. There was a substantial heterogeneity between the included studies. Different kinds of systemic corticosteroids (triamcinolone acetonide and prednisolone) administered in different ways (intramuscular and oral) were compared with different kinds of comparator drugs (indometacine and ACTH). Studies used different inclusion criteria (for example, diagnosis with and without identification of MSU crystals) and different outcome measurements (for example, days until complete resolution, change on a VAS in $\mathrm{mm})$.

5. Two of the three studies had no predesigned method for how to register and analyse adverse effects, and the number of patients was too small to provide a more definitive conclusion about safety. However, safety problems from systemic corticosteroids in a short course of treatment are very unlikely in other medical situations (Rowe 2001; Gotzsche 2005).

The strength of our review is that we searched all available databases, included publications without language restriction, and used independent researchers for inclusion and exclusion (with good kappa values), as well as for data extraction. A limitation was that we did not request additional data from the authors of the excluded or included studies, nor did we request gout experts or pharmaceutical companies to provide unpublished trials.

In conclusion, the efficacy of systemic corticosteroids in acute gout and their effectiveness, equivalent to the regularly used drugs (in particular NSAIDs), require more evidence. Derived from this review, the evidence can be graded as a maximum of Silver according to the four-point scale grading system (Platinum, Gold, Silver, and Bronze) described in the book Evidence-based Rheumatology (Tugwell 2004), and as recommended by the Cochrane Musculoskeletal Review Group.

\section{AUTHORS' CONCLUSIONS}

\section{Implications for practice}

Based on this review, we were not able to define evidence-based implications for medical practice although we expect that systemic corticosteroids could have the potential to become a safe treatment alternative in the management of acute gout.

\section{Implications for research}

Despite the potential of corticosteroids in relieving inflammation in acute gout without important safety problems, the real efficacy and clinical effectiveness requires more evidence. Therefore, welldesigned, high quality trials are necessary. As placebo-controlled studies are hardly feasible because of ethical considerations, we advise randomized double blind equivalence trials with NSAIDs as comparator drugs, given that they have a generally accepted efficacy and effectiveness. Future trialists should be aware of predefined design conditions (for example a power calculation based number of patients, range of equivalence) and the use of comparable outcome measures, for example those recommended by the OMERACT 7 Special Interest group (Schumacher 2005). 


\section{ACKNOWLEDGEMENTS}

We gratefully thank JD Macfarlane for critically reading the manuscript.

\section{RE FER E N C E S}

\section{References to studies included in this review}

\section{Alloway 1993 \{published data only\}}

Alloway JA, Moriarty MJ, Hoogland YT, Nashel DJ. Comparison of triamcinolone acetonide with indomethacin in the treatment of acute gouty arthritis. The Journal of Rheumatology 1993;20(1):111-3. [MEDLINE: 51]

Man 2007 \{published data only\}

Man CY, Cheung IT, Cameron PA, Rainer TH. Comparison of oral prednisolone/paracetamol and oral indomethacin/ paracetamol combination therapy in the treatment of acute goutlike arthritis: a double-blind, randomized, controlled trial. Annals of Emergency Medicine 2007;49:670-7. [MEDLINE: 174]

Siegel 1994 \{published data only\} Siegel LB, Alloway JA, Nashel DJ. Comparison of adrenocorticotropic hormone and triamcinolone acetonide in the treatment of acute gouty arthritis. The Journal of Rheumatology 1994;21(7):1325-7. [MEDLINE: 52]

\section{References to studies excluded from this review}

Axelrod 1988 \{published data only\}

Axelrod D, Preston S. Comparison of parenteral adrenocorticotropic hormone with oral indomethacin in the treatment of acute gout. Arthritis and Rheumatism 1988;31 (6):803-5.

Conaghan 1994 \{published data only\} Conaghan PG, Day RO. Risks and benefits of drugs used in the management and prevention of gout. Drug Safety: an international journal of medical toxicology and drug experience 1994;11(4):252-8. [MEDLINE: 47]

\section{Groff 1990 \{published data only\}}

Groff GD, Franck WA, Raddatz DA. Systemic steroid therapy for acute gout: a clinical trial and review of the literature. Seminars in Arthritis and Rheumatism 1990;19 (6):329-36. [MEDLINE: 50]

Werlen 1996 \{published data only\}

Werlen D, Gabay C, Vischer TL. Corticosteroid therapy for the treatment of acute attacks of crystal-induced arthritis: an effective alternative to nonsteroidal antiinflammatory drugs. Revue du rhumatisme (English edition) 1996;63(4): 248-54. [MEDLINE: 53]

\section{References to ongoing studies}

\section{ISRCTN14648181 \{published data only\}}

* Van de Lisdonk E. Randomised double blind trial of prednisone and naproxen in treatment of crystal proven acute gout. http://www.controlled-trials.com/ ISRCTN14648181/14648181 2005.

\section{Additional references}

\section{Abbott 1988}

Abbott RD, Brand FN, Kannel WB, Castelli WP. Gout and coronary heart disease: the Framingham Study. Journal of Clinical Epidemiology 1988;41:237-42.

\section{Ahern 1987}

Ahern MJ, Reid C, Gordon TP, McCredie M, Brooks PM, Jones M. Does colchicine work? The results of the first controlled study in acute gout. Australian and New Zealand Journal of Medicine 1987;17(3):301-4. [MEDLINE: 45]

\section{Altman 1988}

Altman RD, Honig S LJ, Lightfoot RW. Ketoprofen versus indomethacin in patients with acute gouty arthritis: a multicenter, double blind comparative study. The Journal of Rheumatology 1988;15:1422-6. [MEDLINE: 101]

\section{Arnold 1988}

Arnold MH, Preston SJ, Watson Buchanan W. Comparison of the natural history of untreated acute gouty arthritis vs acute arthritis treated with non-steroidal-anti-inflammatory drugs. British Journal of Clinical Pharmacology 1988;26: 488-9. [MEDLINE: 172]

\section{Arromdee 2002}

Arromdee E, Michet CJ, Crowson CS, O'Fallon WM, Gabriel SE. Epidemiology of gout: is the incidence rising? . The Journal of Rheumatology 2002;29(11):2403-6. [MEDLINE: 1]

\section{Bellamy 1987} Bellamy N, Downie WW, Buchanan WW. Observations on spontaneous improvement in patients with podagra: implications for therapeutic trials of non-steroidal antiinflammatory drugs. British Journal of Clinical Pharmacology 1987;24:33-6. [MEDLINE: 95]

Bieber 2004

Bieber JD, Terkeltaub RA. Gout: on the brink of novel therapeutic options for an ancient disease. Arthritis and Rheumatism 2004;50(8):2400-14. [MEDLINE: 2]

Cates 2003

Chris Cates www.nntonline.com. Visual Rx - NNT Calculator. Chris Cates www.nntonline.com, 2003.

\section{Cohen 1960}

Cohen J. A coefficient of agreement for nominal scales. Educational and Psychological Measurement 1960;20: 37-46. [: Cohen J. A coefficient of agreement for nominal scales. Educational and Psychological Measurement 
1960;20:37-46. Cohen 1960 Cohen J. A coefficient of agreement for nominal scales. Educational and Psychological Measurement 1960;20:37-46. Cohen J. A coefficient of agreement for nominal scales. Educational and Psychological Measurement 1960;20:37-46.]

\section{Fam 1998}

Fam AG. Gout in the elderly. Clinical presentation and treatment. Drugs \& Aging 1998;13(3):229-43. [MEDLINE: 54]

\section{Gotzsche 2005}

Gotzsche PC, Johansen HK. Short-term low-dose corticosteroids vs placebo and nonsteroidal antiinflammatory drugs in rheumatoid arthritis. Cochrane Database of Systematic Reviews 2005, Issue 1. [DOI: 10.1002/14651858.CD000189.pub2; MEDLINE: 180]

\section{Higgins 2002}

Higgins JP, Thompson SG. Quantifying heterogeneity in a meta-analysis. Statistics in Medicine 2002;21(11):1539-58.

\section{Higgins 2005}

Higgins JPT, Green S, editors. Cochrane Handbook for Systematic Reviews of Interventions 4.2.5 [updated May 2005]. www.cochrane.org/resources/handbook/hbook.htm. Chichester, UK: John Wiley \& Sons, Ltd, (accessed 30 August 2005).

\section{Janssens 2003}

Janssens HJEM, Van de Lisdonk EH, Bor H, Van den Hoogen HJM, Janssen M. Gout, just a nasty event or a cardiovascular signal? A study from primary care. Family Practice 2003;20:413-6.

\section{Janssens 2006}

Janssens HJEM, van de Lisdonk EH, Janssen M, van den Hoogen HJM, Verbeek ALM. Gout, not induced by diuretics? A case-control study from primary care. Annals of the Rheumatic Diseases 2006;65:1080-3.

\section{Jones 1996}

Jones B, Jarvis P, Lewis JA, Ebbutt AF. Trials to assess equivalence: the importance of rigorous methods. $B M J$ 1996;313:36-9. [MEDLINE: 179]

\section{Kearney 2006}

Kearney PM, Baigent C, Godwin J, Halls H, Emberson JR, Patrono C. Do selective cyclo-oxygenase-2 inhibitors and traditional non-steroidal anti-inflammatory drugs increase the risk of atherothrombosis? Meta-analysis of randomised trials. BMJ 2006;332:1302-8. [MEDLINE: 176]

\section{Kim 2003}

Kim KY, Schumacher HR, Hunsche E, Wertheimer AI KS A literature review of the epidemiology and treatment of acute gout. Clinical Therapeutics 2003;25(6):1593-617. [MEDLINE: 154]

\section{Krishnan 2006}

Krishnan E, Baker JF, Furst DE, Schumacher HR. Gout and the risk of acute myocardial infarction. Arthritis and Rheumatism 2006;54(8):2688-96. [MEDLINE: 160]

\section{Lewis 2002}

Lewis SC, Langman MJ, Laporte JR, Matthews JN, Rawlins $\mathrm{MD}$, Wiholm BE. Dose-response relationships between individual nonaspirin nonsteroidal anti-inflammatory drugs (NANSAIDs) and serious upper gastrointestinal bleeding: a meta-analysis based on individual patient data. British Journal of Clinical Pharmacology 2002;54:320-6. [MEDLINE: 155]

\section{Maccagno 1991}

Maccagno A, Di Giorgio E, Romanowicz A. Effectiveness of etodolac ('Lodine') compared with naproxen in patients with acute gout. Current Medical Research and Opinion 1991;12(7):423-9. [MEDLINE: 39]

\section{Morris 2003}

Morris I, Varughese G, Mattingly P. Colchicine in acute gout. BMJ 2003;327(7426):1275-6. [MEDLINE: 48]

\section{Perez-Ruiz 2000}

Perez-Ruiz F, Calabozo M, Herrero-Beites AM, GarciaErauskin G, Pijoan JI. Improvement of renal function in patients with chronic gout after proper control of hyperuricemia and gouty bouts. Nephron 2000;86(3): 287-91. [MEDLINE: 44]

\section{Petersel 2007}

Petersel D, Schlesinger N. Treatment of acute gout in hospitalized patients. The Journal of Rheumatology 2007;34 (7):1566-8.

\section{Robinson 2002}

Robinson KA, Dickersin K. Development of a highly sensitive search strategy for the retrieval of reports of controlled trials using PubMed. International Journal of Epidemiology 2002;31(1):150-3. [MEDLINE: 36]

\section{Rowe 2001}

Rowe BH, Spooner C, Ducharme FM, Bretzlaff JA, Bota GW. Early emergency department treatment of acute asthma with systemic corticosteroids. Cochrane Database of Systematic Reviews 2001, Issue 1. [DOI: 10.1002/ 14651858.CD002178\%C2\%A0; MEDLINE: 177]

\section{Rubin 2004}

Rubin BR, Burton R, Navarra S, Antigua J, Londono J, Pryhuber KG, et al.Efficacy and safety profile of treatment with etoricoxib $120 \mathrm{mg}$ once daily compared with indomethacin $50 \mathrm{mg}$ three times daily in acute gout: a randomized controlled trial. Arthritis and Rheumatism 2004;50(2):598-606. [MEDLINE: 175]

\section{Schlesinger 2004}

Schlesinger N. Management of acute and chronic gouty arthritis: present state-of-the-art. Drugs 2004;64(21): 2399-416. [MEDLINE: 3]

\section{Schlesinger 2006} Schlesinger N, Schumacher HR, Catton M, Maxwell L. Colchicine for acute gout. Cochrane Database of Systematic Reviews 2006, Issue 4. [DOI: 10.1002/ 14651858.CD006190; MEDLINE: 182]

\section{Schumacher 1996}

Schumacher HR. Crystal-induced arthritis: an overview. The American Journal of Medicine 1996;100(2A):46S-52S. [MEDLINE: 55] 


\section{Schumacher 2002}

Schumacher HR Jr, Boice JA, Daikh DI, Mukhopadhyay S, Malmstrom K, Ng J, Tate GA, Molina J. Randomised double blind trial of etoricoxib and indometacin in treatment of acute gouty arthritis. BMJ 2002;324(7352): 1488-92. [MEDLINE: 41]

\section{Schumacher 2005}

Schumacher HR Jr, Edwards LN P-RF, Becker M, Chen LX, Furst DE, Joseph-Ridge N, et al.Outcome measures for acute and chronic gout. The Journal of Rheumatology 2005; 32:2452-5. [MEDLINE: 183]

\section{Shrestha 1995}

Shrestha M, Morgan DL, Moreden JM, Singh R, Nelson M, Hayes JE. Randomized double-blind comparison of the analgesic efficacy of intramuscular ketorolac and oral indomethacin in the treatment of acute gouty arthritis. Annals of Emergency Medicine 1995;26(6):682-6. [MEDLINE: 40]

Sturge 1977

Sturge RA, Scott JT, Hamilton EB, Liyanage SP, Dixon AS, Davies J, Engler C. Multicentre trial of naproxen and phenylbutazone in acute gout. Annals of the Rheumatic Diseases 1977;36(1):80-2. [MEDLINE: 38]

\section{Sutaria 2006}

Sutaria S, Katbamna R, Underwood M. Effectiveness of interventions for the treatment of acute and prevention of recurrent gout - a systematic review. Rheumatology (Oxford) 2006;45:1422-31. [MEDLINE: 153]

Terkeltaub 2003

Terkeltaub RA. Clinical practice. Gout. New England Journal of Medicine 2003;349(17):1647-55. [MEDLINE: 4]

\section{Tugwell 2004}

Tugwell P, Shea B, Boers M, Brooks P, Simon L, Strand V, et al.Evidence Based Rheumatology. BMJ Books, 2004.

\section{Underwood 2006}

Underwood M. Diagnosis and management of gout. BMJ 2006;332:1315-9. [MEDLINE: 145]

\section{Van de Lisdonk 2003}

Van de Lisdonk EH, Van den Bosch WJHM, Huygen FJA, Lagro-Janssen ALM. Diseases in general practice. Ziekten in de Huisartspraktijk. 4th Edition. Maarssen: Elsevier, 2003.

\section{Van der Linden 2004}

Van der Linden MW, Wetsert GP, De Bakker DH, Schellevis FG. Illness and disease in the community and family practice [Klachten en aandoeningen in de bevolking en in de huisartspraktijk]. Tweede Nationale Studie naar ziekten en verrichtingen in de huisartspraktijk. Utrecht, Bilthoven: NIVEL, Rijksinstituut voor Volksgezondheid en Milieu, 2004 (available from: http://www.nivel.nl/pdf/ ns2_rapport1.pdf). [MEDLINE: http://www.nivel.nl/ pdf/ns2_rapport1.pdf; : http://www.nivel.nl/pdf/ ns2_rapport1.pdf]

Wallace 1977

Wallace SL, Robbinson H, Masi AT, Decker JL, McArty DJ, Yü T. Preliminary criteria for the classification of the acute arthritis of primary gout. Arthritis and Rheumatism 1977;20(3):895-900.

\section{Wise 1996}

Wise CM, Agudelo CA. Gouty arthritis and uric acid metabolism. Current Opinion in Rheumatology 1996;8(3): 248-54. [MEDLINE: 49]

* Indicates the major publication for the study 


\section{CHARACTERISTICS OF STUDIES}

\section{Characteristics of included studies [ordered by study ID]}

Alloway 1993

\begin{tabular}{|c|c|c|}
\hline Methods & \multicolumn{2}{|c|}{ Active comparator controlled non-randomized trial; non blinded } \\
\hline Participants & \multicolumn{2}{|c|}{$\begin{array}{l}27 \text { patients (all men) presenting at a hospital rheumatology department with acute gout, diagnosed after } \\
\text { MSU-crystal identification }\end{array}$} \\
\hline Interventions & \multicolumn{2}{|c|}{$\begin{array}{l}14 \text { patients received a systematic corticosteroid: triamcinolone acetonide (TCA) } 60 \mathrm{mg} \text { by intramuscula } \\
\text { injection, and if necessary a number of additional injections; } 13 \text { controls received oral indomethacin } \\
\text { (IDN) } 50 \mathrm{mg} \text { TID, with the permission to taper their medication after at least } 2 \text { days in response to } \\
\text { symptomatic improvement (control therapy). TCA treated patients were given additionally paracetamo } \\
\text { with codeine for analgesia }\end{array}$} \\
\hline Outcomes & \multicolumn{2}{|c|}{$\begin{array}{l}\text { The symptomatic improvement on a 5-point scale, the number of active joints, presence of toxicity, and } \\
\text { presence of rebound arthropathy. The final efficacy outcome was the number of days required for total } \\
\text { resolution of all symptoms, and in addition, the clinical joint status at } 3 \text { follow-up moments }\end{array}$} \\
\hline Notes & \multicolumn{2}{|c|}{$\begin{array}{l}\text { No outcome measurement by the patient. } 4 \text { patients in the TCA group and } 3 \text { in the IDM group were los } \\
\text { to follow up }\end{array}$} \\
\hline \multicolumn{3}{|l|}{ Risk of bias } \\
\hline Item & Authors' judgement & Description \\
\hline Allocation concealment? & Unclear & B - Unclear \\
\hline
\end{tabular}

Man 2007

\begin{tabular}{l|l}
\hline Methods & Active comparator controlled randomized trial; double blinded \\
\hline Participants & $\begin{array}{l}90 \text { patients presenting at a university hospital emergency department with an acute arthritis clinically } \\
\text { "suggestive of gout" }\end{array}$ \\
\hline Interventions & $\begin{array}{l}44 \text { patients (male } 35) \text { received a systematic corticosteroid: } 30 \mathrm{mg} \text { oral prednisolone daily for } 5 \text { days. } 46 \\
\text { (male } 39) \text { patients received indomethacine (IDM) } 50 \mathrm{mg} \text { TID for } 2 \text { days and } 25 \mathrm{mg} \text { TID for } 3 \text { days after } 1 \\
\text { initial intramuscular injection with } 75 \mathrm{mg} \text { diclofenac (control therapy). In both treatment arms additional } \\
\text { paracetamol } 1000 \mathrm{mg} \text { every } 4 \text { hours as required }\end{array}$ \\
\hline Outcomes & Pain reduction at rest, as with activity, scored on a visual analogue scale of $10 \mathrm{~cm}$ \\
\hline Notes & 7 patients, all from the IDM group, had to stop the study medication because of adverse effects \\
\hline
\end{tabular}

Risk of bias 
Man 2007 (Continued)

\begin{tabular}{l|ll}
\hline Item & Authors' judgement & Description \\
\hline Allocation concealment? & Yes & A - Adequate \\
\hline
\end{tabular}

\section{Siegel 1994}

\begin{tabular}{|c|c|c|}
\hline Methods & \multicolumn{2}{|c|}{ Active comparator randomized controlled trial; non blinded. } \\
\hline Participants & \multicolumn{2}{|c|}{$\begin{array}{l}31 \text { patients (all men) presenting at a hospital rheumatology department with acute gout, diagnosed after } \\
\text { MSU-crystal identification }\end{array}$} \\
\hline Interventions & \multicolumn{2}{|c|}{$\begin{array}{l}16 \text { patients received a systematic corticosteroid: triamcinolone acetonide } 60 \mathrm{mg} \text { by intramuscular injection. } \\
15 \text { received adrenocorticotropic hormone (ACTH) } 40 \mathrm{IU} \text { by intramuscular injection (control therapy). } \\
\text { If necessary a number of additional injections was given in both treatment arms }\end{array}$} \\
\hline Outcomes & \multicolumn{2}{|c|}{$\begin{array}{l}\text { Patient's improvement of pain, mobility, and swelling on a } 5 \text {-point scale, the number of active joints, the } \\
\text { joint status, side effects, and presence of rebound arthropathy. The final efficacy outcome was the number } \\
\text { of days required for total resolution of all symptoms }\end{array}$} \\
\hline Notes & \multicolumn{2}{|c|}{$\begin{array}{l}\text { One patient allocated to ACTH treatment was not characterized, and lost to follow up. Two patients of } \\
\text { the ACTH group were excluded from the analysis because of insufficient response }\end{array}$} \\
\hline \multicolumn{3}{|l|}{ Risk of bias } \\
\hline Item & Authors' judgement & Description \\
\hline Allocation concealment? & Unclear & B - Unclear \\
\hline
\end{tabular}

\section{Characteristics of excluded studies [ordered by study ID]}

\begin{tabular}{ll}
\hline Study & Reason for exclusion \\
\hline Axelrod 1988 & Systematic corticosteroids not studied. \\
\hline Conaghan 1994 & Non-systematic review; no clinical trial. \\
\hline Groff 1990 & Prospective, non-controlled trial. \\
\hline Werlen 1996 & $\begin{array}{l}\text { No outcome measurement by the patient. No differentiation between patients with gout and patients with chon- } \\
\text { drocalcinosis }\end{array}$ \\
\hline
\end{tabular}




\section{Characteristics of ongoing studies [ordered by study ID]}

\section{ISRCTN14648181}

\begin{tabular}{|c|c|}
\hline Trial name or title & Randomized double-blind trial of prednisone and naproxen in treatment of crystal proven acute gout \\
\hline \multicolumn{2}{|l|}{ Methods } \\
\hline Participants & Primary care gout patients diagnosed after the identification of MSU crystals \\
\hline Interventions & $\begin{array}{l}\text { Five days, by oral administration, either prednisolon } 35 \mathrm{mg}(=30 \mathrm{mg} \text { prednisone }) \text { once a day or naproxen at } \\
\text { a dose of } 500 \mathrm{mg} \text { twice a day. Patients received blind capsules containing active prednisolon and placebo } \\
\text { naproxen, or active naproxen and placebo prednisolon }\end{array}$ \\
\hline Outcomes & $\begin{array}{l}\text { Primary outcomes: Patient assessment of pain in the study joint, indicated on visual analogical scales two } \\
\text { times a day, during } 4 \text { days ; Secondary outcomes: } 1 \text {. Patient's global disability } \\
\text { 2. The walking disability, if the study joint was in the leg or foot } \\
\text { 3. Safety and tolerability of prednisone versus naproxen. }\end{array}$ \\
\hline Starting date & April 1st 2004 \\
\hline Contact information & $\begin{array}{l}\text { Dr E van de Lisdonk, Department of General Practice and Family Medicine 229, Radboud University } \\
\text { Nijmegen Medical Centre } \\
\text { PO Box 9191, Nijmegen, } 6500 \mathrm{HB} \text {, The Netherlands, Tel }+31 \text { (0)24 } 36\end{array}$ \\
\hline Notes & \\
\hline
\end{tabular}


DATA AND ANALYSES

This review has no analyses.

ADDITIONAL TABLES

Table 1. Quality of studies

\begin{tabular}{|c|c|c|c|c|c|c|c|c|}
\hline Study & $\begin{array}{l}\text { Randomi- } \\
\text { sation }\end{array}$ & $\begin{array}{l}\text { Allocation } \\
\text { conceal. }\end{array}$ & $\begin{array}{l}\text { Treatment } \\
\text { blinding }\end{array}$ & $\begin{array}{l}\text { ITT analy- } \\
\text { sis }\end{array}$ & $\begin{array}{l}\text { Total drop- } \\
\text { out }\end{array}$ & $\begin{array}{l}\text { Selective } \\
\text { drop-out }\end{array}$ & $\begin{array}{l}\text { Blind out- } \\
\text { come-assess }\end{array}$ & $\begin{array}{l}\text { Overall } \\
\text { quality }\end{array}$ \\
\hline & $\begin{array}{l}\mathrm{A}=\text { adequate } \\
\mathrm{B}= \\
\text { unknown or } \\
\text { inadequate }\end{array}$ & $\begin{array}{l}\mathrm{A}=\text { adequate } \\
\mathrm{B}= \\
\text { unknown or } \\
\text { inadequate }\end{array}$ & $\begin{array}{l}\mathrm{A}= \\
\text { adequate } \mathrm{B}= \\
\text { blinding but } \\
\text { method un- } \\
\text { clear } \\
\mathrm{C}=\text { non- } \\
\text { blinded, in- } \\
\text { adequate, or } \\
\text { unknown }\end{array}$ & $\begin{array}{l}\mathrm{A}= \\
\text { adequate } \mathrm{B}= \\
\text { ITT inade- } \\
\text { quate } \mathrm{C}=\mathrm{un}- \\
\text { clear or no } \\
\text { re- } \\
\text { ported data } \\
\text { on drop-out } \\
\text { or loss to fol- } \\
\text { low up }\end{array}$ & $\begin{array}{l}\mathrm{A}<15 \% \\
\mathrm{~B}>/=15 \% \text { or } \\
\text { unknown }\end{array}$ & $\begin{array}{l}\begin{array}{l}\mathrm{A}=\text { differ- } \\
\text { ence in } \\
\text { drop-out }\end{array} \\
\text { rate in main } \\
\text { groups }<10 \% \\
\mathrm{~B}>/=10 \% \text { or } \\
\text { unknown }\end{array}$ & $\begin{array}{l}\mathrm{A}=\text { adequate } \\
\mathrm{B}=\text { mention- } \\
\text { ing of blind- } \\
\text { ing but exact } \\
\text { method un- } \\
\text { clear } \mathrm{C}=\text { non } \\
\text { blinded, in- } \\
\text { adequate or } \\
\text { unknown }\end{array}$ & $\begin{array}{l}\mathrm{A}=\text { all quality } \\
\text { criteria met } \\
\mathrm{B}=\text { one or } \\
\text { more quality } \\
\text { criteria only } \\
\text { partially met } \\
\mathrm{C}=\text { one or } \\
\text { more criteria } \\
\text { not met }\end{array}$ \\
\hline $\begin{array}{l}\text { Alloway } \\
1993\end{array}$ & B & B & C & C & B & A & C & C \\
\hline $\begin{array}{l}\text { Man } \\
2007\end{array}$ & A & A & B & A & A & B & C & B \\
\hline $\begin{array}{l}\text { Siegel } \\
1994\end{array}$ & B & B & $\mathrm{C}$ & $\mathrm{C}$ & A & A & C & $\mathrm{C}$ \\
\hline
\end{tabular}

Table 2. Efficacy results of included studies

\begin{tabular}{|c|c|c|c|c|}
\hline Study & $\mathbf{n}$ & Outcome & Results & Note \\
\hline \multirow[t]{2}{*}{ Alloway 1993} & $I=14 ; C=13$ & $\begin{array}{l}\text { Average number of days } \\
\text { until complete resolution }\end{array}$ & $\begin{array}{l}\text { I } 7.4 \text { (SD 4.55); C } 8.3 \\
\text { (SD4.35); Difference } 0.9 \\
\mathrm{p}=0.66\end{array}$ & $\begin{array}{l}3 \text { of } 10 \text { patients received a } \\
\text { second injection (= I). Lost } \\
\text { to follow up: } n=7 \text { (I: } n=4 ; \\
\text { C: } n=3 \text { ) }\end{array}$ \\
\hline & & $\begin{array}{l}\text { Mean joint score after } 1 \text { to } \\
2,3 \text { to } 4 \text {, and } 10 \text { to } 14 \text { days } \\
\text { (5-point scale: } 0=\text { total res- } \\
\text { olution, } 1=\text { improvement of } \\
>50 \%, 2=\text { improvement of } \\
<50 \%, 3=\text { no change, } 4= \\
\text { worsening of symptoms) }\end{array}$ & $\begin{array}{l}\text { I: } 1.0(\mathrm{SD} 0.72) \text { to } 0.62 \\
\text { (SD } 0.78) \text { to } 0.50 \text { (SD } 0 \text {. } \\
\text { 16). } \\
\text { C: } 1.5(S D 0.85) \text { to } 0.65 \\
\text { (SD } 0.63) \text { to } 0.20 \text { (SD } 0 . \\
\text { 37); Differences: } 0.5(\mathrm{p}=0 . \\
\text { 24), } 0.03(\mathrm{p}=0.94) \text {, and }-0 . \\
30(\mathrm{p}=025)\end{array}$ & $\begin{array}{l}3 \text { of } 10 \text { patients received a } \\
\text { second injection }(=\mathrm{I}) .7 \text { pa- } \\
\text { tients were lost to follow up } \\
(\mathrm{I}: \mathrm{n}=4 ; \mathrm{C}: \mathrm{n}=3)\end{array}$ \\
\hline
\end{tabular}




\begin{tabular}{|c|c|c|c|c|}
\hline Mann 2007 & $I=44 ; C=46$ & $\begin{array}{l}\text { Mean decrease ( } \mathrm{mm} \text { on a } \\
\text { VAS) per hour of pain at } \\
\text { rest within the first } 2 \text { hours }\end{array}$ & $\begin{array}{l}\text { I }-9.5 \text { (SD 10.5); C }-6.4 \\
\text { (SD 8.3); Difference } 3.2 \\
(95 \% \text { CI }-0.78 \text { to } 7.14), p= \\
0.12\end{array}$ & $\begin{array}{l}\text { The difference in mean } \\
\text { pain score was at no time } \\
\text { more than } 13 \mathrm{~mm} \text {, which } \\
\text { was unlikely to be clinically } \\
\text { relevant according to the } \\
\text { authors }\end{array}$ \\
\hline & & $\begin{array}{l}\text { Mean decrease ( } \mathrm{mm} \text { on a } \\
\text { VAS) per hour of pain dur- } \\
\text { ing activity within the first } \\
2 \text { hours }\end{array}$ & $\begin{array}{l}\text { I }-19.2 \text { (SD 11.2); C }-20 \text {. } \\
3 \text { (SD 9.1); Difference }-1.1 \\
\text { (95\%CI: } \\
-5.34 \text { to } 3.24), p=0.63\end{array}$ & $\begin{array}{l}\text { The difference in mean } \\
\text { pain score was at no time } \\
\text { more than } 13 \mathrm{~mm} \text {, which } \\
\text { was unlikely to be clinically } \\
\text { relevant according to the } \\
\text { authors }\end{array}$ \\
\hline & & $\begin{array}{l}\text { Mean decrease ( } \mathrm{mm} \text { on a } \\
\text { VAS) per day of pain at rest } \\
\text { after } 2 \text { weeks }\end{array}$ & $\begin{array}{l}\text { I }-0.7 \text { (SD 1.2); C }-0 . \\
3 \text { (SD0.7); Difference } 0.5 \\
\text { (95\%CI: } 0.03 \text { to } 0.89), p= \\
0.04\end{array}$ & $\begin{array}{l}\text { The difference in mean } \\
\text { pain score was at no time } \\
\text { more than } 13 \mathrm{~mm} \text {, which } \\
\text { was unlikely to be clinically } \\
\text { relevant according to the } \\
\text { authors. } \\
\text { Lost to follow up: } \mathrm{n}=7 \text { (I: } \\
\left.\mathrm{n}=0 \text {; C: } \mathrm{n}=7^{*}\right)^{*} \text { had to stop } \\
\text { the study after adverse ef- } \\
\text { fects }\end{array}$ \\
\hline & & $\begin{array}{l}\text { Mean decrease ( } \mathrm{mm} \text { on a } \\
\text { VAS) per day of pain dur- } \\
\text { ing activity after } 2 \text { weeks }\end{array}$ & $\begin{array}{l}\text { I }-2.9 \text { (SD 2.0); C }-1.7 \\
(S D 1.6) ; \text { Difference } 1.2 \\
(95 \% \text { CI: } 0.44 \text { to } 2.00) . p= \\
0.0026\end{array}$ & $\begin{array}{l}\text { The difference in mean } \\
\text { pain score was at no time } \\
\text { more than } 13 \mathrm{~mm} \text {, which } \\
\text { was unlikely to be clinically } \\
\text { relevant according to the } \\
\text { authors. } \\
\text { Lost to follow up: } \mathrm{n}=7 \text { (I: } \\
\left.\mathrm{n}=0 \text {; C: } \mathrm{n}=7^{*}\right)^{*} \text { had to stop } \\
\text { the study after adverse ef- } \\
\text { fects }\end{array}$ \\
\hline \multirow[t]{2}{*}{ Siegel 1994} & $I=16 ; C=15$ & $\begin{array}{l}\text { Average number of days } \\
\text { until complete resolution }\end{array}$ & $\begin{array}{l}\text { I 7.6; 7.9; Difference } 0.3 \\
p=0.89\end{array}$ & $\begin{array}{l}4 \text { of } 16 \text { patients required a } \\
\text { second I-injection, } 9 \text { of } 14 \\
\text { a second C-injection. } 3 \text { pa- } \\
\text { tients required a third C-in- } \\
\text { jection. } \\
\text { Lost to follow up: } n=3 \text { (I: } \\
\left.\mathrm{n}=0 \text {; C: } n=3^{*}\right) * 2 \text { because of } \\
<50 \% \text { improvement after } 3 \\
\text { C-injections }\end{array}$ \\
\hline & $\begin{array}{l}\mathrm{I}=\text { Intervention; } \mathrm{C}=\text { Con- } \\
\text { trol }\end{array}$ & & $\mathrm{SD}=$ Standard Deviation & \\
\hline
\end{tabular}




\section{A P P E N D I C E S}

\section{Appendix I. MEDLINE search strategy}

\#1 Gout

"gout" [mh] OR gout* [tw] OR "Hyperuricemia”[mh] OR toph* [tw] OR arthritis uric* [tw] OR artritis uric* [tw] OR uric acid dis* $[\mathrm{tw}]$

\#2 Corticosteroids

"Glucocorticoids" [mh] OR “Adrenal Cortex Hormones" [mh] OR "Steroids"[mh] OR glucocortic* [tw] OR adrenal Cortex Horm* [tw] OR prednison* [tw] OR prednisol* [tw] OR cortison* [tw] OR hydrocort* [tw] OR methylprednis* [tw] OR triamcinol* [tw] OR dexamethas* [tw] OR betamethas* [tw] OR beclomethas* [tw] OR paramethas* [tw] OR dexametas* [tw] OR betametas* [tw] OR beclometas* $[\mathrm{tw}]$ OR parametas* $[\mathrm{tw}]$

\#3 Controlled trials

(Randomized controlled trial [pt] OR controlled clinical trial [pt] OR randomized controlled trials [mh] OR random allocation [mh] OR double-blind method [mh] OR single-blind method [mh] OR clinical trial [pt] OR clinical trials [mh] OR (clinical trial [tw]) OR ((singl* $\left.{ }^{*} \mathrm{tw}\right]$ OR doubl* [tw] OR trebl* [tw] OR tripl* [tw]) AND (mask* [tw] OR blind* [tw])) OR (latin square [tw]) OR placebos [mh] OR placebo* [tw] OR random* [tw] OR research design [mh:noexp] OR comparative study [mh] OR evaluation studies [mh] OR follow-up studies [mh] OR prospective studies [mh] OR cross-over studies [mh] OR control* [tw] OR prospectiv* [tw] OR volunteer* [tw]) NOT (animal [mh] NOT human [mh])

Whole search

\#1 AND \#2 AND \#3

Abbreviations: mh: exploded medical subject heading (Medline medical index term); mh:noexp: non-exploded medical subject heading $\left(\right.$ MEDLINE medical index term); $\mathrm{tw}=$ text word; $\mathrm{pt}=$ publication type. The asterisk $\left(^{*}\right)$ stands for any character $(s)$.

\section{WHAT'S NEW}

Last assessed as up-to-date: 7 December 2007.

\begin{tabular}{|c|c|c|}
\hline Date & Event & Description \\
\hline 22 April 2008 & Amended & $\begin{array}{l}\text { Converted to new review format. } \\
\text { CMSG ID: C155-R }\end{array}$ \\
\hline
\end{tabular}

\section{H IS T O R Y}

Protocol first published: Issue 4, 2005

Review first published: Issue 2, 2008 


\section{CONTRIBUTIONS OFAUTHORS}

HEIN JANSSENS: conceived the review; selected the studies and assessed the quality; extracted and analyzed the data; wrote the manuscript of the protocol and the article; edited the protocol and the article.

PETER LUCASSEN: selected the studies and assessed the quality; extracted and analyzed the data; contributed to the writing of the manuscript of the protocol and the article, reviewed the manuscript of the protocol and the article.

FLORIS VAN DE LAAR: contributed to the writing of the manuscript and the article; reviewed the manuscript of the protocol and the article; contributed to the editing of the protocol and the article.

MATTHIJS JANSSEN: contributed to the conception of the review; reviewed the manuscript of the protocol and the article.

ELOY VAN DE LISDONK: contributed to the conception of the review; reviewed the manuscript of the protocol and the article.

\section{DECLARATIONS OF INTEREST}

All the authors declared no possible conflict of interest.

\section{SOURCES OFSUPPORT}

\section{Internal sources}

- Radboud University Nijmegen Medical Centre, Netherlands.

\section{External sources}

- No sources of support supplied

\section{N DEX TERMS}

\section{Medical Subject Headings (MeSH)}

Acute Disease; Adrenal Cortex Hormones [administration \& dosage; ${ }^{*}$ therapeutic use]; Adrenocorticotropic Hormone [therapeutic use]; Gout [ ${ }^{*}$ drug therapy]; Indomethacin [therapeutic use]; Triamcinolone [therapeutic use]

\section{MeSH check words}

Humans 